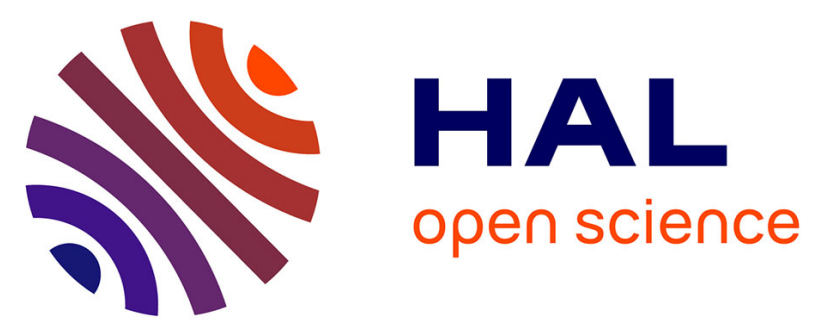

\title{
Coupling powder bed additive manufacturing and vapor phase deposition methods for elaboration of coated 3D Ti-6Al-4V architectures with enhanced surface properties
}

\author{
A. Moll, J.-J. Blandin, R. Dendievel, E. Gicquel, M. Pons, Carmen Jiménez, \\ E. Blanquet, F. Mercier
}

\section{To cite this version:}

A. Moll, J.-J. Blandin, R. Dendievel, E. Gicquel, M. Pons, et al.. Coupling powder bed additive manufacturing and vapor phase deposition methods for elaboration of coated 3D Ti-6Al-4V architectures with enhanced surface properties. Surface and Coatings Technology, 2021, 415, pp.127130. 10.1016/j.surfcoat.2021.127130 . hal-03262005

\section{HAL Id: hal-03262005 \\ https://hal.science/hal-03262005}

Submitted on 16 Jun 2021

HAL is a multi-disciplinary open access archive for the deposit and dissemination of scientific research documents, whether they are published or not. The documents may come from teaching and research institutions in France or abroad, or from public or private research centers.
L'archive ouverte pluridisciplinaire HAL, est destinée au dépôt et à la diffusion de documents scientifiques de niveau recherche, publiés ou non, émanant des établissements d'enseignement et de recherche français ou étrangers, des laboratoires publics ou privés. 


\title{
Coupling Powder Bed Additive Manufacturing and Vapor Phase Deposition Methods \\ for Elaboration of Coated 3D Ti-6Al-4V Architectures with Enhanced Surface
}

\section{Properties}

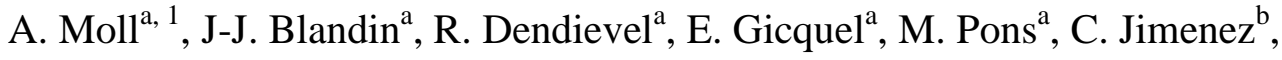 \\ E. Blanquet ${ }^{\mathrm{a}}, \mathrm{F}$. Mercier ${ }^{\mathrm{a}}, 1$ \\ ${ }^{a}$ Univ. Grenoble Alpes, CNRS, Grenoble INP, SIMaP, F-38000 Grenoble, France \\ ${ }^{\mathrm{b}}$ Univ. Grenoble Alpes, CNRS, Grenoble INP, LMGP, F-38000 Grenoble, France
}

\begin{abstract}
We propose an innovative process coupling powder bed additive manufacturing by Electron Beam Melting (EBM) with Chemical Vapor Deposition (CVD) and Atomic Layer Deposition (ALD) to develop 3D Ti-6Al-4V structures covered with AlN coating. Despite of the high reactivity of Ti-6Al-4V with nitrogen, thick $(\sim 10 \mu \mathrm{m})$ and conformal AlN films are deposited by CVD on Ti-6Al-4V substrates with high surface roughness. An AlN under-layer deposited by ALD is necessary to mitigate the reaction between Ti-6Al-4V and the nitrogen precursor $\mathrm{NH}_{3(\mathrm{~g})}$ and to limit the formation of brittle titanium nitride phases. We have thus achieved an adherent coating without any modification of the Ti-6Al-4V microstructure at the core of the substrate. We show that a $7 \mu \mathrm{m}$ thick AlN coating is efficient in protecting Ti-6Al-4V against cyclic oxidation at $650^{\circ} \mathrm{C}$ for at least $650 \mathrm{~h}$. This study opens new opportunities for the design of coated 3D Ti-6Al-4V structures for use in high temperature oxidizing environments.
\end{abstract}

Keywords: Coating, Titanium alloys, Nitrides, Barrier layer, CVD, Oxidation

\footnotetext{
${ }^{1}$ Corresponding authors: moll@icmpe.cnrs.fr (A. Moll), frederic.mercier@ simap.grenoble-inp.fr (F. Mercier) Present Addresses: A. Moll, now at Univ. Paris Est Creteil, CNRS, ICMPE, UMR 7182, Thiais 94320, France
} 


\section{Introduction}

Powder bed additive manufacturing technics have been widely developed these last decades for their unique performance in the processing of complex and tailored metallic objects. Among the existing technologies, Electron Beam Melting (EBM) involves the layer-by-layer addition of pre-alloyed powders selectively melted with a high-energy electron beam scanning the sample from a Computer-Aided Design (CAD) model [1]. A large set of metals such as Co-, Ni-based alloys or copper have already been manufactured by EBM [1]. The Ti-6Al-4V (wt. \%) alloy, is one of the most studied materials for EBM fabrication [2-7]. The structure of the Ti-6Al-4V alloy is a mixture of hcp $\alpha$-Ti and bcc $\beta$-Ti phases stabilized by $\mathrm{Al}$ and $\mathrm{V}$ respectively. It is largely used in the aeronautics and biomedical industries $[8,9]$. Thanks to EBM technology, there is a growing interest in Ti-6Al-4V 3D structures generally known as "lattice structures", for weight reduction or mechanical properties adjustment for example.

One of the limitations of using Ti-6Al-4V in aeronautic applications is its low oxidation resistance at temperatures above $400{ }^{\circ} \mathrm{C}$ [10]. To increase the working temperature limit, Ti6Al-4V has been coated with different materials [11], e.g. materials based on Ti-Al [12-14], Ti-Al-Nb-Si [15], TiAl(Si)N [16, 17], NiCrAl [18], Nb [19], $\mathrm{Y}_{2} \mathrm{O}_{3}$ [20], $\mathrm{SiO}_{2}-\mathrm{Al}_{2} \mathrm{O}_{3}$ [21]. Corrosion prevention at temperatures from 600 to $900^{\circ} \mathrm{C}$ can be achieved. To our knowledge, aluminium nitride (AlN) coating has never been reported on Ti-6Al-4V despite its high oxidation resistance at temperature below $800^{\circ} \mathrm{C}[22,23]$ and its high temperature stability. The deposition processes of AlN are currently well developed in the industry and can easily be adapted for Ti-6Al-4V coating. Moreover, interesting physical properties of AlN such as high thermal conductivity and piezoelectric properties make it interesting for further surface functionalization of Ti-6Al-4V which could be on high interest by combination with EBM. 
To our knowledge, such structures combining vapor-phase coatings and EBM have never been reported in literature. One of the major challenges for coating of EBM manufactured Ti$6 \mathrm{Al}-4 \mathrm{~V}$ is the typical high roughness resulting from numerous surface irregularities [24]. Due to the complexity of the lattice structures, the usual surface preparation such as machining or polishing cannot be carried out prior to the coating deposition. Some suitable methods were reported for coating of metallic additive manufacturing [25]. For example, electrospark or electrophoretic depositions were used respectively for coating of Inconel 625 by aluminum alloy [26] and Ti implants by Chitosan-based layer with silver nanoparticules [27]. Soaking of Ti-6Al-4V structures fabricated by additive manufacturing in simulated body fluid also produces hydroxyapatite coating [28]. Finally, TiO2 coatings were reported by surface oxidation by anodizing [29, 30], plasma oxidation [31] or plasma electrolytic oxidation [32, 33]. Nevertheless only a conformal and isotropic technique as the chemical vapor phase deposition methods can be applied for the formation of high temperature protection coatings of the 3D lattice structures having high surface roughness.

The Atomic Layer Deposition (ALD) technique is the most favorable one, but is not suitable for the deposition of the micrometer-thick films necessary for oxidation protection. Thick films can be deposited by Chemical Vapor Deposition (CVD). However, a higher temperature than ALD must be used to grow the films, which can induce thermal stress, chemical reactions or microstructural modifications of the Ti-6Al-4V substrate. Chemical reactions and diffusion at the coating/substrate interface occurring during high temperature process can sometimes be beneficial. For example, nitrogen diffusion was observed during coating of stainless steel by $\mathrm{TiN}$ by plasma nidation of $\mathrm{Ti}$ layer at temperature above $650^{\circ} \mathrm{C}$ [34]. The authors showed the formation of a 10-15 $\mu \mathrm{m}$ nitrogen-rich austenite layer (expanded austenite) at the interface, improving the wear resistance and harness of the materials. Wear resistance improvement was also observed in $\mathrm{Cp}$ - $\mathrm{Ti}$ coated by $\mathrm{TiO}_{2}$ due to oxygen diffusion 
of $60-150 \mu \mathrm{m}$ [31]. Nevertheless, when detrimental, these interface reactions should be avoided for example by addition of a protective layer.

In this paper, the growth of aluminum nitride (AlN) coatings is carried out on Ti-6Al-4V substrates manufactured by EBM using a combination of ALD and CVD processes. The effect of an intermediate ALD layer is studied to limit chemical reactions and diffusion due its lower processing temperature. Moreover, the high conformity of ALD process ensures full coverage of the surface of Ti-6Al-4V even in the narrower defects. The high temperature CVD process was selected for the deposition of micrometer-thick coating thanks to its appreciable growth rate (few $\mu \mathrm{m} / \mathrm{h}$ ). To our knowledge, this study shows for the first time the potentiality of chemical vapor deposition techniques like CVD and ALD for the coating of EBM structures. This study also suggests the use of AlN coating for high temperature oxidation protection of Ti-6Al-4V. In the first part of this paper, the morphology of a film deposited at high temperature by CVD directly on the Ti-6Al-4V alloy and its interface with the substrate are presented. Then, the effect of an intermediate layer of AlN deposited by ALD is discussed. Finally, the enhancement of oxidation resistance of EBM Ti-6Al-4V alloy through the AlN coating protection is shown at $650^{\circ} \mathrm{C}$. By implementation of the process on 3D lattice substrates, we thus open new prospects in the use of complex and tailored structures in hot environment.

\section{Materials and methods}

\subsection{Materials and manufacturing}

Parallelepiped Ti-6Al-4V substrates (Fig. 1a ) and 3D lattice structures (Fig. 1b) were prepared using an ARCAM A1 EBM machine and Ti-6Al-4V ELI grade 23 powder with an average particle size of $50 \mu \mathrm{m}$ and chemical composition given in Table 1. An accelerating 
voltage of $60 \mathrm{kV}$ was applied under He atmosphere at $2 \times 10^{-3} \operatorname{mbar}[24,35,36]$. The surface roughness of the as-built substrates, observed in Fig. 1c and 1d, is the result of surface irregularities from two types of defects: not-fully-melted particles stuck to the structure leading to the formation of spherical defects, and irregularities in the layer stacking ("platepile" like defects) [24]. The roughness was measured by contact profilometer (Form Talysurf 50, Taylor Hobson) giving a mean roughness value, $\mathrm{R}_{\mathrm{a}}=33 \mu \mathrm{m}$. The SEM cross-section observation of the $\alpha+\beta$ microstructure of the Ti-6Al-4V is given in Supporting Information (Fig. S1).

CVD AlN coatings were obtained in a home-built vertical reactor working with a cold-wall configuration at low pressure $[37,38]$ (schematic representation in Fig. S2a in Supporting Information). The aluminum precursor was $\mathrm{AlCl}_{3}$ formed by in situ chlorination from Aluminum pellets (Goodfellow Company, 99.999\%) and $\mathrm{Cl}_{2(\mathrm{~g})}(20 \mathrm{sccm}, 99.999 \%)$. The chlorination zone was heated by a resistive system at $\sim 540^{\circ} \mathrm{C}$. AlN growth was achieved by the reaction between $\mathrm{NH}_{3(\mathrm{~g})}(40 \mathrm{sccm}, 99.999 \%)$ and $\mathrm{AlCl}_{3(\mathrm{~g})}$. $\mathrm{H}_{2}(99.999 \%)$ was used as the carrier gas with a flow rate of $2250 \mathrm{sccm}$.

Substrates were cleaned in an ultrasonic bath with ethanol and acetone. A graphite susceptor was heated by induction using a RF coil and the temperature was measured on the graphite using a $\mathrm{N}$-type thermocouple. After reaching the chlorination and deposition temperatures and before introduction of the reactants, the $\mathrm{Al}$ pellets and the Ti-6Al-4V substrate were cleaned under $\mathrm{H}_{2}(2250 \mathrm{sccm})$ for $20 \mathrm{~min}$. This step also ensured the temperature stabilization of the substrates. As the properties of the Ti-6Al-4V alloy depend strongly on its microstructure, it is important to limit the Ti-6Al-4V microstructure modifications during the AlN deposition process by working at temperatures below the transus limit reported at $995^{\circ} \mathrm{C}$ for $\mathrm{Ti}-6 \mathrm{Al}-4 \mathrm{~V}$ [39]. The Ti-6Al-4V substrates were coated at $850^{\circ} \mathrm{C}$ and 20 mbar with a deposition rate of about $4 \mu \mathrm{m} / \mathrm{h}$. After deposition, cooling was made under $\mathrm{N}_{2}$ with a $2250 \mathrm{sccm}$ flow rate and a 
20 mbar pressure. The film thicknesses were measured by cross-section observations using a Scanning Electron Microscopy (SEM) (see part 2.3).

Plasma-Enhanced ALD (PEALD) of AIN was made in a Picosun R-200 reactor at $350^{\circ} \mathrm{C}$ [40]. The $\mathrm{Al}$ and $\mathrm{N}$ precursors were trimethylaluminium (TMA, 99.99\%, STREM) and $\mathrm{NH}_{3}$ (99.99\%, Air Liquide), respectively. The cycle consisted on a TMA pulse of $0.1 \mathrm{~s}$ with a $4 \mathrm{~s}$ purge, $12 \mathrm{~s}$ of $\mathrm{H}_{2}$ plasma activation and $\mathrm{NH}_{3}$ pulse of $5 \mathrm{~s}$ with $4 \mathrm{~s}$ purge time. ALD film thicknesses were measured by ellipsometry with a Semilab SE-2000 apparatus using a reference film deposited on Si wafer during the same run. The shape and coating operations of the samples used in this study are described in Table 2.

Table 1: Chemical composition of Ti-6Al-4V (wt.\%)

\begin{tabular}{llllllll}
\hline Al & $\mathrm{V}$ & $\mathrm{C}$ & $\mathrm{Fe}$ & $\mathrm{O}$ & $\mathrm{N}$ & $\mathrm{H}$ & $\mathrm{Ti}$ \\
6.47 & 3.93 & 0.01 & 0.22 & 0.09 & 0.01 & 0.001 & Balance \\
\hline
\end{tabular}

Table 2: Designation and description of the coatings used in this study.

\begin{tabular}{ccc}
\hline Designation & Manufactured shape & Coating technique (thickness) \\
\hline Coating 1 & Parallelepiped & CVD $(10 \mu \mathrm{m})$ \\
Coating 2 & Parallelepiped & $A L D(300 \mathrm{~nm})+C V D(10 \mu \mathrm{m})$ \\
Coating 3 & Parallelepiped & $A L D(140 \mathrm{~nm})+C V D(7 \mu \mathrm{m})$ on both faces \\
Coating 4 & Lattice & $A L D(140 \mathrm{~nm})+C V D(1-13 \mu \mathrm{m})$ \\
\hline
\end{tabular}

\subsection{Oxidation tests}


Cyclic oxidation tests were carried out under natural air at $650 \pm 2{ }^{\circ} \mathrm{C}$ in a Nabertherm P330 tubular furnace in open air equipped with a clean silica tube. The temperature at the sample location was previously checked with a calibrated probe. A parallelepiped Ti-6Al-4V substrate with a $7 \mu \mathrm{m}$ thick AlN coating on both faces was tested (Coating 3 in Table 2) with a non-coated reference also manufactured by EBM. They were placed side by side in individual silica flat crucibles. The furnace was pre-heated before the introduction of the sample and its temperature was kept constant during the whole test. Thus, the oxidation cycle consists in placing the samples directly in the hot furnace for dwelling time from $1 \mathrm{~h}$ to $142 \mathrm{~h}$ and removing them from the furnace for natural cool down. The two samples were then weighted at room temperature with a laboratory digital balance with a precision of $0.1 \mathrm{mg}$. Each point in the graph in Figure 8 corresponds with one cycle. A special care was taken to avoid film deterioration and to collect delaminated parts of the uncoated sample in the bottom of the crucible.

\subsection{Characterization}

Scanning Electron Microscope (SEM) observations were performed with a JEOL JSMIT500HR LV microscope and equipped with an Energy Dispersive Spectroscopy (EDS) equipment. Prior to the observation, the coated samples were metallized with carbon. Crosssections were prepared by fixing the coated Ti-6Al-4V in an epoxy resin, cutting and polishing from 600 grit $(26 \mu \mathrm{m}) \mathrm{SiC}$ paper to $1 \mu \mathrm{m}$ polycrystalline diamond suspension.

The cross-sections of samples prepared by Focus Ion Beam (FIB, ZEISS NVision 40) were analyzed by Transmission Electron Microscopy (TEM) combined with the ASTAR/ ACOM technique which enables phase and orientation mapping at the nanometric scale (probe size of $2 \mathrm{~nm}$ in our conditions) by identifying the electronic diffraction pattern at each position [41, 42]. A JEOL 2100F- 200 kV FEG apparatus was used. 
X-Ray Diffraction (XRD) was performed in $\theta / 2 \theta$ configuration with a Bruker D8 Advance diffractometer equipped with a copper source. Pattern matchings were carried out with FullProf software for the determination of lattice parameter [43].

\section{Results and discussion}

\subsection{Direct AIN coating by CVD}

The surface morphology of the Ti-6Al-4V substrate before (Fig. 1) and after AlN deposition (Fig.2) by CVD (Coating 1 in Table 2) were characterized by SEM. The aspect of the AlNcoated Ti-6Al-4V surface is similar to that of the uncoated substrate shown in Fig. 1b. The chemical composition is homogeneous along the surface as observed in BSE images in Fig. 2a (grey contrasts are due to shadowing effects). XRD and EDS analysis confirm the AlN composition of the film with a preferential orientation along the [0001] direction. The lattice parameters obtained from pattern matching are $\mathrm{a}=3.120 \AA$ and $\mathrm{c}=4.991 \AA$ (Fig. S4 and Table S1, in Supporting Information). They are slightly higher than the reported values $(\mathrm{a}=$ $3.111 \AA ̊, c=4.978 \AA$ from ICDD PDF 00-066-0534). The atomic contents measured by EDS of $\mathrm{Al}$ and $\mathrm{N}$ are $49 \%$ and $48 \%$, respectively. Traces of $\mathrm{Cl}$, coming from the process, and $\mathrm{O}$ are also detected. The AlN film presents a cauliflower morphology observed at higher magnification (Fig. 2b).

Cross-section observation (Fig.3a) shows a conformal $10 \mu \mathrm{m}$ thick AlN film in dark contrast around the Ti-6Al-4V substrate. A good coverage is confirmed even in the narrower defects as that shown in Fig. 3b. The high deposition rate of the CVD process enables large surface and roughness reductions. We measured for example a surface reductions of $30 \%$ by deposition of a $40 \mu \mathrm{m}$ thick AlN coating (see Fig. S3 in Supporting Information). 
It is important to mention that the usual $\alpha+\beta$ microstructure of the Ti- $6 \mathrm{Al}-4 \mathrm{~V}$ substrate is preserved after the CVD process.

However, a nitrogen-rich region at the Ti-6Al-4V/coating interface is visible in Fig. 3b. The presence of two titanium nitride phases, $\mathrm{TiN}$ and $\mathrm{Ti}_{2} \mathrm{~N}$, is confirmed by XRD (Fig. S4). By further analyzing this region with the TEM/ASTAR technique (Fig. 4), several layers are identified. It is a stack of a $400-700 \mathrm{~nm}$ thick $\mathrm{Ti}_{2} \mathrm{~N}$ layer covered with a $300-400 \mathrm{~nm}$ thick TiN layer, then AlN. Clear interfaces are visible between each layer in Fig. 4b. In the substrate, at the upper interface, a $\alpha-\operatorname{Ti}(\mathrm{N})$ solid solution of about $5.8 \mu \mathrm{m}$ thickness is formed by nitrogen diffusion. The $\beta$-Ti phase is not detected in this region showing that microstructure is locally modified near the substrate surface. The initial microstructure of Ti-6Al-4V is finally observed by SEM under the diffusion zone. This $\mathrm{TiN}^{\mathrm{T}} \mathrm{Ti}_{2} \mathrm{~N} / \alpha-\mathrm{Ti}(\mathrm{N}) / \mathrm{Ti}-6 \mathrm{Al}-4 \mathrm{~V}$ stack is similar to the microstructures reported in the case of Ti-6Al-4V nitriding $[44,45]$. The formation of TiN and $\mathrm{Ti}_{2} \mathrm{~N}$ during the AlN deposition results from two phenomena. First, the reaction of the Ti-6Al-4V substrate with $\mathrm{NH}_{3}$ (g) occurs during the first stages of the CVD process due to the lower free enthalpy of formation of titanium nitrides than that of AlN (values are given in Fig. S5 in Supporting Information). Additionally, the formation of the titanium nitrides layers can be induced by the solid reaction between the freshly formed AlN and the Ti-6Al-4V substrate at high temperature because of the higher stability of $\operatorname{TiN}$ and $\mathrm{Ti}_{2} \mathrm{~N}$ with respect to AlN. In the Al-N-Ti system, AlN and $\mathrm{Ti}$ are not in equilibrium and the system will evolve towards the formation of intermediate compounds such as $\mathrm{TiN} \mathrm{Ti}_{2} \mathrm{~N}$ or even a ternary compound such as $\mathrm{Ti}_{2} \mathrm{AlN}$ and $\mathrm{Ti}_{3} \mathrm{AlN}$. We do not observe the formation of $\mathrm{Ti}_{2} \mathrm{AlN}$ and $\mathrm{Ti}_{3} \mathrm{AlN}$. This behavior can be explained by the relatively high partial pressure of nitrogen in the experimental conditions used (well above $10^{-16}$ atm), which prevents the formation of these ternary compounds [46]. Finally no evidence of the presence of $\mathrm{Al}$ in the TiN structure is found (no formation of $\mathrm{Ti}_{1-\mathrm{x}} \mathrm{Al}_{\mathrm{x}} \mathrm{N}$ solid solution). 
As shown in Fig. 4a and Fig. 5, the $\alpha$-Ti(N) region is brittle and leads in a delamination of the coating from the substrate. The presence of holes at the interface between the $\operatorname{Ti}_{2} \mathrm{~N}$ and the $\alpha$ $\operatorname{Ti}(\mathrm{N})$ layers in Fig. $4 \mathrm{~b}$ confirms the brittleness of the material resulting from the $\alpha-\operatorname{Ti}(\mathrm{N})$ formation while a good adherence of the $\mathrm{AlN}$ film on $\mathrm{TiN}$ and $\mathrm{Ti}_{2} \mathrm{~N}$ is observed. This brittleness is particularly visible during the FIB preparation (Fig. 5a) preventing the use of these coating for any further application. As reported by Zhang et al. [16] in the case of a TiAlN coating on Ti-6Al-4V, the volume expansion and the changes on the thermal expansion coefficients induced by the titanium nitriding lead to residual stress explaining crack formation.

The deposition conditions for the AIN CVD coating thus induce a modification of the surface microstructure of Ti-6Al-4V due to nitrogen diffusion. The brittleness of the $\alpha-\operatorname{Ti}(\mathrm{N})$ layer can strongly limit the potential applications. To circumvent these drawbacks, the possibility of limiting titanium nitriding by depositing an additional AlN buffer layer by ALD is explored in the next section.

\subsection{Mitigating the chemical reactivity with an ALD buffer layer}

In the previous section, the formation of $\mathrm{TiN}$ and $\mathrm{Ti}_{2} \mathrm{~N}$ is related to i) the reaction between $\mathrm{NH}_{3(\mathrm{~g})}$ and the Ti-6Al-4V substrate during CVD deposition and, ii) the solid state reaction between the AlN coating and the substrate. The latter reaction cannot be avoided during the growth of the coating at high temperature. To control the diffusion of nitrogen from the $\mathrm{NH}_{3}$ (g) gas phase into the Ti-6Al-4V substrate during the growth of the coating, a $300 \mathrm{~nm}$ thick AlN layer is deposited by the ALD process before the CVD process (Coating 2 in Table 2). Fig. 6a shows SEM cross-sections and has to be compared with Fig. 4. The addition of the ALD layer improves the quality of the interface and avoid delamination of the AlN film. The ASTAR mapping (Fig. 6b) shows a 300 nm-thick layer at the interface made of a mixture of TiN and $\alpha$-Ti grains due to nitrogen diffusion, and with a smooth interface with the $\alpha$-Ti(N) 
zone. It can be pointed out that the thickness of this layer is the same as the TiN layer thickness measured in the case of direct CVD deposition. The $\mathrm{Ti}_{2} \mathrm{~N}$ phase is not detected. The thickness of the $\alpha-\operatorname{Ti}(\mathrm{N})$ solid solution also decreases from $5.8 \mu \mathrm{m}$ in the previous section to $1.8 \mu \mathrm{m}$. The AlN layer deposited by ALD limits the exposure of the substrate to $\mathrm{NH}_{3}(\mathrm{~g})$ during the growth of the layer by CVD. As a result, the formation of nitrided phases at the interface with the substrate is considerably reduced, as confirmed by XRD analysis (Fig. S6). The only possibility of nitride formation is the result of the reaction between the AlN layer and the Ti-6Al-4V substrate. Additionally, stress reduction by the combination of the i) formation of the mixing microstructure of the $\mathrm{TiN}$ layer, ii) absence of $\mathrm{Ti}_{2} \mathrm{~N}$ formation and iii) reduction of the thickness of $\alpha-\operatorname{Ti}(\mathrm{N})$ zone, leads to the non-failure of the nitrided zone and avoid delamination of the coating. Another advantage of depositing the ALD undercoating is the guaranteed coverage of small features due to the high conformity of the ALD process (as shown by the SEM in Fig. S7).

The microstructural analysis of the AIN coating obtained by CVD with an ALD buffer layer is shown in Fig. 7. A columnar morphology of AlN is observed for both ALD and CVD layers with a preferential growth orientation along the [0001] direction, as confirmed by XRD and as previously observed without an ALD buffer layer (XRD pattern in Fig. S6 in Supporting Information). Therefore, the addition of an ALD sub-layer does not affect the preferential orientation of the AlN coating. As a consequence of local homoepitaxy of the CVD film on each grain of the ALD layer, no clear interface can be observed between ALD and CVD layers. Then, a grain coarsening can be noticed during CVD growth, increasing the grain size in the CVD film from about $100 \mathrm{~nm}$ in diameter in the ALD layer to $2.3 \mu \mathrm{m}$ after CVD of a 3 $\mu \mathrm{m}$ thick film. Therefore, CVD reduces the amount of grain boundaries in the film when compared to the ALD layer. The decrease in the density of grain boundaries is beneficial when considering protection against oxidation. 


\subsection{Enhancement of surface properties of EBM Ti-6Al-4V}

\subsubsection{Protection of EBM Ti-6Al-4Vagainst cyclic oxidation}

We studied the cyclic oxidation behavior of AlN coated (ALD + CVD, total thickness $\sim 7 \mu \mathrm{m}$, Coating 3 in Table 2) and non-coated EBM Ti-6Al-4V at $650^{\circ} \mathrm{C}$ at atmospheric pressure in air, and the mass gain for both samples as a function of time are presented in Fig. 8. The oxidation kinetic follows the law:

$$
\left(\frac{\Delta m}{S}\right)^{n}=k_{n} t
$$

with $\Delta m / S$ the mass gain per surface unit, $n$, the rate exponent, $k_{n}$ the rate constant and $t$ the oxidation time.

The oxidation behavior of non-coated EBM Ti-6Al-4V follows a nearly parabolic oxidation rate with $n=1.7$ and $k_{n}=1.48 \times 10^{-2} \mathrm{mg}^{2} \cdot \mathrm{cm}^{-4} \cdot \mathrm{h}^{-1}$. These results are in good agreement with reported values on Ti-6Al-4V obtained by conventional processing at $650^{\circ} \mathrm{C}$ such as $n=1.7$ and $k_{n}=1.43 \times 10^{-2} \mathrm{mg}^{2} \cdot \mathrm{cm}^{-4} \cdot \mathrm{h}^{-1}$ [47] or $n=1.8$ and $k_{n}=1.53 \times 10^{-2} \mathrm{mg}^{2} \cdot \mathrm{cm}^{-}$ ${ }^{4} \cdot \mathrm{h}^{-1}[48]$. Therefore, the oxidation behavior of the Ti-6Al-4V alloy obtained by EBM appears similar to the oxidation behavior of a Ti-6Al-4V alloy obtained by conventional processing. The oxidation of Ti-6Al-4V is characterized by the formation of $\mathrm{TiO}_{2}$ and $\mathrm{Al}_{2} \mathrm{O}_{3}$ as shown by XRD (Fig. 9a) and described in references [48, 49].

For AlN-coated structures, a clear reduction of the oxidation kinetics can be observed. The mass gain is below $0.1 \mathrm{mg} / \mathrm{cm}^{2}$ during about $100 \mathrm{~h}$ whereas this value is reached during the first $4 \mathrm{~h}$ for non-coated materials. After $650 \mathrm{~h}$, the mass gain values are $0.42 \mathrm{mg} / \mathrm{cm}^{2}$ and 3.66 $\mathrm{mg} / \mathrm{cm}^{2}$ for coated and non-coated materials, respectively. The coated material follows the kinetic law with $n=1.5$ and $k_{n}=4.43 \times 10^{-4} \mathrm{mg}^{2} \cdot \mathrm{cm}^{-4} \cdot \mathrm{h}^{-1}$, as shown by the dashed line in Fig. 8a. Thus, the rate constant, $k_{n}$, is dramatically reduced compared to the non-coated Ti- 
6Al-4V. A high oxidation resistance of AlN is reported in literature for temperatures below $800^{\circ} \mathrm{C}$ under air $[22,23]$, but to our knowledge, the study of AlN behavior under cyclic oxidation and for hundreds of hours at $650^{\circ} \mathrm{C}$ was never reported. Our oxidation rates cannot therefore be compared with literature data.

XRD patterns (Fig. 9), SEM observations and EDS maps after cyclic oxidation of $490 \mathrm{~h}$ (Fig. 10), confirm the preservation of the AlN coating. The adherence of the AlN film is conserved and no clear alteration nor cracks can be noticed. Nevertheless, the formation of a thin $\mathrm{Al}_{2} \mathrm{O}_{3}$ (corundum) layer at the surface of the coating inferred by EDS and is confirmed by XRD with the presence of the diffraction plans (113) and (116) at $43.3^{\circ}$ and $57.5^{\circ}$, showing that the AlN film is not totally inert in our conditions. The $\mathrm{Al}_{2} \mathrm{O}_{3}$ diffraction peaks are identified from 230 $\mathrm{h}$ and slightly increase with time showing that AlN slowly reacts with oxygen to form a nonprotective $\mathrm{Al}_{2} \mathrm{O}_{3}$ layer at the surface. Nevertheless, the $\mathrm{AlN}$ consumption is low compared to the film thickness. The $\mathrm{TiO}_{2}$ (rutile) phase is also detected by XRD from $40 \mathrm{~h}$ with a slightly increasing diffraction peaks (110), (211) and (220) at $27.4^{\circ}, 54.2^{\circ}$ and $56.5^{\circ}$, but is not observed by SEM. The $\mathrm{TiO}_{2}$ formation, which also seems very low after $490 \mathrm{~h}$, can be due to oxygen diffusion through the AlN coating. The combination of these two effects together can explain the slight mass gain. Finally, nitrogen diffusion at the coating/substrate interface can be detected over a distance of $2.4 \mu \mathrm{m}$ after $490 \mathrm{~h}$ by EDS but without any detrimental effect on the adherence even under hard cyclic temperature variations.

Thus, we show that AlN coatings radically reduce the oxidation rate and provide an excellent protection of EBM Ti-6Al-4V for at least $650 \mathrm{~h}$ against cyclic oxidation at $650^{\circ} \mathrm{C}$.

\subsubsection{Coating of 3D Ti-6Al-4V structures.}

The major interest of EBM is the possibility to process 3D structures. In Fig. 11, we show that CVD and ALD techniques are well adapted for the coating of lattice Ti-6Al-4V structures with $30 \times 30 \mathrm{~mm}^{2}$ dimensions (Coating 4 in Table 2). Further experimental details of these 
techniques are given in Supporting Information (Fig. S2). As opposed to "line-of-sight" deposition techniques such as physical vapor deposition (PVD), chemical reactions gas-phase based ALD and CVD have the capability to grow uniform and conformal films in 3D structures with complex shapes and in general terms with large aspect ratios. As shown before, coupling ALD and CVD enables to take advantages of both technics: thick coating deposition and roughness reduction by CVD, and reactivity mitigation and filling of narrow defects by ALD.

Although the CVD process has still to be optimized to improve thickness homogeneity and growth rate of the coating, an AlN film covering the entire 3D substrate is observed in Fig. 11. The coating thickness has been measured along the lattice length by SEM and is given in Fig. 12. Film thicknesses of about $13 \mu \mathrm{m}$ are observed on the top of the lattice structure, in direct exposition with the reactive gas flux. Below, a nearly homogeneous film is observed from about $5 \mathrm{~mm}$ to the bottom of the lattice structure, with thicknesses around $1 \mu \mathrm{m}$. Thus, this process coupling EBM manufacturing, ALD and CVD opens new opportunities to address the development of complex and coated Ti-6Al-4V structures.

With adjusting pressure and exposure time, the Chemical Vapor Infiltration (CVI), alternative to classical CVD would definitely be even more efficient to cover the inside part of a porous material [50]. Using realistic CVI conditions and parameters, the optimum densification conditions could be found that result in better coverage. Besides, ALD using exposure mode available in T-ALD has proved its ability to infiltrate a porous media [40]. This function provides the isolation between the reactor and the pump so that lengthening the time available for precursor diffusion and surface reactions on substrates for coating high aspect ratio structures, which makes it comparable to CVI. 


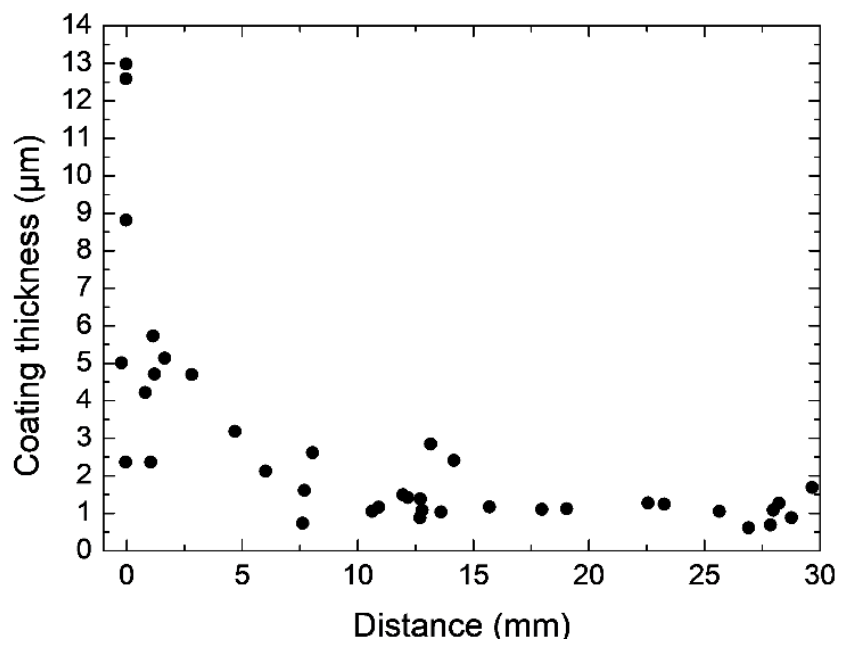

Fig 12: Thickness of AlN coating on 3D lattice structure. The distance origin is the top of the lattice.

\section{Conclusions}

EBM elaborated Ti-6Al-4V substrates were coated with AlN thick films using CVD and ALD deposition processes, directly or successively. The following results were obtained:

- When using only CVD, thick and conformal films covering the entire structure were achieved. Nevertheless, the nitriding of Ti-6Al-4V led to the formation of an interface composed of a stack of three layers, $\operatorname{TiN}, \operatorname{Ti}_{2} \mathrm{~N}$ and a brittle $\alpha-\operatorname{Ti}(\mathrm{N})$ diffusion zone resulting in the delamination of the coating. This effect is due both to the reaction between $\mathrm{NH}_{3(\mathrm{~g})}$ and the Ti-6Al-4V substrate and to the solid state reaction between the AlN coating and the substrate.

- By depositing a $300 \mathrm{~nm}$ thick AlN buffer layer by ALD before implementing the CVD process, the nitriding can be limited and an adherent coating is achieved.

- Coupling CVD and ALD enables to take advantages of both techniques: due to high deposition rate, CVD process enables thick coatings deposition and roughness reduction. The low temperature and high conformity of ALD techniques is interesting to mitigate the reactivity between substrate and CVD coating, and to fill narrow defects. 
- The AlN crystalline orientation is along the [0001] direction with local epitaxy of the CVD film on each grain of the ALD layer.

- Because the deposition temperature was limited to $850^{\circ} \mathrm{C}$, no change in the microstructure of the Ti-6Al-4V alloy was observed in its bulk.

- For the first time, a good protection of EBM Ti-6Al-4V was shown against cyclic oxidation at $650^{\circ} \mathrm{C}$ for at least $650 \mathrm{~h}$ by an AlN coating.

- As this process can easily be adapted to the coating of 3D lattice structures, this study opens new perspectives for the use of complex structures in high temperature oxidizing environments.

\section{Acknowledgements}

This work was performed within the framework of the Centre of Excellence of Multifunctional Architectured Materials "CEMAM" (grant number ANR-10-LABX-44-01) and with the support from the ANR MAD_Ceramics [grant number ANR-17-CE08-0028]. The authors would like to thank and Guilhem Martin (SIMaP, Grenoble, France) for the preparation of 3D architectures, Thierry Encinas (CMTC,Grenoble, France) for XRD diffraction, Frédéric Charlot (CMTC,Grenoble, France) for FIB preparation and Gilles Renou (CMTC, Grenoble, France) for ASTAR/ACOM imaging. 


\section{References}

[1] L.E. Murr, S.M. Gaytan, Electron beam melting, in: S.Hashmi (Ed.) Comprehensive Materials Processing, Newnes, 2014.

[2] O.L.A. Harrysson, O. Cansizoglu, D.J. Marcellin-Little, D.R. Cormier, H.A. West, Mater. Sci. Eng., C, 28 (2008) 366-373.

[3] G. Chahine, M. Koike, T. Okabe, P. Smith, R. Kovacevic, JOM, 60 (2008) 50-55.

[4] L.E. Murr, S.M. Gaytan, F. Medina, E. Martinez, J.L. Martinez, D.H. Hernandez, B.I. Machado, D.A. Ramirez, R.B. Wicker, Mater. Sci. Eng., A, 527 (2010) 1861-1868.

[5] S.J. Li, L.E. Murr, X.Y. Cheng, Z.B. Zhang, Y.L. Hao, R. Yang, F. Medina, R.B. Wicker, Acta Mater., 60 (2012) 793-802.

[6] X.Z. Zhang, M. Leary, H.P. Tang, T. Song, M. Qian, Curr. Opin. Solid. State Mater. Sci., 22 (2018) 7599.

[7] K. Sofinowski, M. Šmíd, I. Kuběna, S. Vivès, N. Casati, S. Godet, H. Van Swygenhoven, Acta Mater., 179 (2019) 224-236.

[8] C. Leyens, M. Peters, Titanium and Titanium Alloys: Fundamentals and Applications, John Wiley \& Sons, 2003.

[9] R.R. Boyer, Mater. Sci. Eng., A, 213 (1996) 103-114.

[10] R. Boyer, E.W. Collings, G. Welsch, in: Materials Properties Handbook: Titanium Alloys, ASM International, 1994, pp. 484.

[11] C. Leyens, Oxidation and Protection of Titanium Alloys and Titanium Aluminides, in: C. Leyens, M. Peters (Eds.) Titanium and Titanium Alloys: Fundamentals and Applications, John Wiley \& Sons, 2003, pp. 216.

[12] J. Dai, F. Zhang, A. Wang, H. Yu, C. Chen, Surf. Coat. Technol., 309 (2017) 805-813.

[13] C. Chen, X. Feng, Y. Shen, J. Alloys Compd., 813 (2020) 152223.

[14] Z.G. Zhang, Y.P. Peng, Y.L. Mao, C.J. Pang, L.Y. Lu, Corros. Sci., 55 (2012) 187-193.

[15] J. Dai, N. Zhang, A. Wang, H. Zhang, C. Chen, J. Alloys Compd., 765 (2018) 46-57.

[16] M. Zhang, Y. Cheng, L. Xin, J. Su, Y. Li, S. Zhu, F. Wang, Corros. Sci., 166 (2020) 108476.

[17] L. Xin, Q. Chen, Y. Teng, W. Wang, A. Sun, S. Zhu, F. Wang, Surf. Coat. Technol., 228 (2013) 48-58.

[18] Y. Li, C. Chen, T. Han, J. Ranabhat, X. Feng, Y. Shen, J. Alloys Compd., 697 (2017) 268-281.

[19] H.L. Du, P.K. Datta, J.S. Burnell-Gray, D.B. Lewis, J. Mater. Sci., 30 (1995) 2640-2647.

[20] R. Siab, G. Bonnet, J.M. Brossard, J. Balmain, J.F. Dinhut, Appl. Surf. Sci., 253 (2007) 3425-3431.

[21] W. Li, S. Zhu, C. Wang, M. Chen, M. Shen, F. Wang, Corros. Sci., 74 (2013) 367-378.

[22] J.W. Lee, I. Radu, M. Alexe Journal of Materials Science: Materials in Electronics, 13 (2002) 131137.

[23] D. Chen, J. Colas, F. Mercier, R. Boichot, L. Charpentier, C. Escape, M. Balat-Pichelin, M. Pons, Surf. Coat. Technol., 377 (2019) 124872.

[24] P. Lhuissier, C. de Formanoir, G. Martin, R. Dendievel, S. Godet, Materials \& Design, 110 (2016) 485-493.

[25] E. Maleki, S. Bagherifard, M. Bandini, M. Guagliano, Additive Manufacturing, 37 (2021) 101619.

[26] P.D. Enrique, E. Marzbanrad, Y. Mahmoodkhani, Z. Jiao, E. Toyserkani, N.Y. Zhou, Surf. Coat. Technol., 362 (2019) 141-149.

[27] M. Croes, S. Bakhshandeh, I.A.J. van Hengel, K. Lietaert, K.P.M. van Kessel, B. Pouran, B.C.H. van der Wal, H.C. Vogely, W. Van Hecke, A.C. Fluit, C.H.E. Boel, J. Alblas, A.A. Zadpoor, H. Weinans, S. Amin Yavari, Acta Biomater, 81 (2018) 315-327.

[28] C. Yan, L. Hao, A. Hussein, Q. Wei, Y. Shi, Materials science \& engineering. C, Materials for biological applications, 75 (2017) 1515-1524.

[29] K.C. Nune, R.D.K. Misra, X. Gai, S.J. Li, Y.L. Hao, J. Biomater. Appl., 32 (2018) 1032-1048.

[30] S. Amin Yavari, Y.C. Chai, A.J. Bottger, R. Wauthle, J. Schrooten, H. Weinans, A.A. Zadpoor, Materials science \& engineering. C, Materials for biological applications, 51 (2015) 132-138.

[31] H. Kovacı, Surf. Coat. Technol., 374 (2019) 987-996. 
[32] I.A.J. van Hengel, M. Riool, L.E. Fratila-Apachitei, J. Witte-Bouma, E. Farrell, A.A. Zadpoor, S.A.J. Zaat, I. Apachitei, Biomaterials, 140 (2017) 1-15.

[33] Z. Gorgin Karaji, R. Hedayati, B. Pouran, I. Apachitei, A.A. Zadpoor, Materials science \& engineering. C, Materials for biological applications, 76 (2017) 406-416.

[34] M. Yazıcı, H. Kovacı, A.F. Yetim, A. Çelik, Ceramics International, 44 (2018) 14195-14201.

[35] T. Persenot, A. Burr, G. Martin, J.-Y. Buffiere, R. Dendievel, E. Maire, Int. J. Fatigue, 118 (2019) 65-76.

[36] C. de Formanoir, M. Suard, R. Dendievel, G. Martin, S. Godet, Addit. Manuf., 11 (2016) 71-76.

[37] R. Boichot, A. Claudel, N. Baccar, A. Milet, E. Blanquet, M. Pons, Surf. Coat. Technol., 205 (2010) 1294-1301.

[38] M. Pons, R. Boichot, N. Coudurier, A. Claudel, E. Blanquet, S. Lay, F. Mercier, D. Pique, Surf. Coat. Technol., 230 (2013) 111-118.

[39] M. Peters, J. Hemptenmacher, J. Kumpfert, C. Leyens, Structure and Properties of Titanium and Titanium Alloys, in: C. Leyens, M. Peters (Eds.) Titanium and Titanium Alloys: Fundamentals and Applications, John Wiley \& Sons, 2003, pp. 20.

[40] L. Tian, S. Ponton, M. Benz, A. Crisci, R. Reboud, G. Giusti, F. Volpi, L. Rapenne, C. Vallée, M. Pons, A. Mantoux, C. Jiménez, E. Blanquet, Surf. Coat. Technol., 347 (2018) 181-190.

[41] E.F. Rauch, J. Portillo, S. Nicolopoulos, D. Bultreys, S. Rouvimov, P. Moeck, Z. Kristall., 225 (2010).

[42] E.F. Rauch, M. Véron, Mater. Charact., 98 (2014) 1-9.

[43] J. Rodriguez-Carvajal, Abstract of the Satellite Meeting on Powder Diffraction of the XV Congress of the IUCr, Toulouse, France, (1990) 127.

[44] D.B. Lee, I. Pohrelyuk, O. Yaskiv, J.C. Lee, Nanoscale Res Lett, 7 (2012) 21.

[45] A. Zhecheva, W. Sha, S. Malinov, A. Long, Surf. Coat. Technol., 200 (2005) 2192-2207.

[46] F. Mercier, H. Shimoda, S. Lay, M. Pons, E. Blanquet, CrystEngComm, 20 (2018) 1711-1715.

[47] B. Champlin, L. Graff, M. Armand, G. Béranger, C. Coddet, J. Less Common Met., 69 (1980) 163183.

[48] S. Frangini, A. Mignone, F. De Riccardis, J. Mater. Sci., 29 (1994) 714-720.

[49] H.L. Du, P.K. Datta, D.B. Lewis, J.S. Burnell-Gray, Corros. Sci., 34 (1994) 631-642.

[50] G.L. Vignoles, C. Gaborieau, S. Delettrez, G. Chollon, F. Langlais, Surf. Coat. Technol., 203 (2008) 510-515. 


\section{List of figure captions}

Fig. 1. a) As-built parallelepiped and b) lattice Ti-6Al-4V substrates elaborated by EBM. c) SEM observation of the surface of an as-built parallelepiped substrate. d) Cross-section observation of a strut of lattice structure with vertical manufacturing orientation.

Fig. 2. (a) Homogeneous chemical composition and (b) Cauliflower morphology of the AlN coating deposited by CVD on Ti-6Al-4V substrate revealed by surface SEM observation. BSE: back-scattered electrons, SE: secondary electron

Fig. 3. Conformal coverage of the Ti-6Al-4V substrate (light contrast) by a $10 \mu \mathrm{m}$ thick AlN film (dark contrast) deposited by CVD observed by cross-section SEM. a) Large view b) Magnification on a narrow defect. A nitrogen-rich region indicated by the arrow is shown at the AlN / Ti-6Al-4V interface.

Fig. 4. Observation of the nitrogen-rich region at the interface between the Ti-6Al-4V substrate and AlN CVD film. a) Cross-section SEM observation showing the formation of a brittle $5.8 \mu \mathrm{m}$ thick $\alpha$-Ti(N) solid solution. b) Phase cartography by TEM/ASTAR revealing a $\mathrm{TiN} / \mathrm{Ti}_{2} \mathrm{~N}$ stacking between the AlN film and $\alpha-\mathrm{Ti}(\mathrm{N})$.

Fig. 5. a) Brittle $\alpha-\mathrm{Ti}(\mathrm{N})$ interface of the AlN CVD coated Ti-6Al-V surface observed during the TEM preparation by FIB. b) Break of the AlN / Ti-6Al-4V interface due to the formation of brittle $\alpha-\operatorname{Ti}(\mathrm{N})$ solid solution.

Fig. 6. Improvement of the AlN / Ti-6Al-4V interface compared to Fig. 4. by addition of a $300 \mathrm{~nm}$-thick AlN buffer by ALD limiting the nitrogen diffusion. a) SEM cross-section observation showing the formation of a $1.8 \mu \mathrm{m}$ thick $\alpha-\operatorname{Ti}(\mathrm{N})$ solid solution. b) Phase cartography by TEM/ASTAR revealing a $300 \mathrm{~nm}$ - thick layer made of a TiN and $\alpha$-Ti mixture. The $\mathrm{Ti}_{2} \mathrm{~N}$ phase is not detected. 
Fig. 7. TEM-ASTAR analysis of the CVD AlN film on the top of a $300 \mathrm{~nm}$ thick ALD predeposition a) phase cartography b) crystallographic orientation along the growth direction.

Fig. 8. Oxidation protection of EBM Ti-6Al-4V by a $7 \mu \mathrm{m}$ thick AlN coating (ALD +CVD) at $650^{\circ} \mathrm{C}$. The mass gain during cyclic oxidation under air is compared to uncoated EBM Ti6Al-4V. The dashed lines show the kinetic laws with $n=1.5$ and $k_{n}=4.43 \times 10^{-4} \mathrm{mg}^{2} . \mathrm{cm}^{-}$ ${ }^{4} \cdot \mathrm{h}^{-1}$ for AlN-coated Ti-6Al-4V and $n=1.7$ and $k_{n}=1.48 \times 10^{-2} \mathrm{mg}^{2} \cdot \mathrm{cm}^{-4} \cdot \mathrm{h}^{-1}$ for uncoated Ti-6Al-4V.

Fig. 9. XRD patterns of a) uncoated EBM Ti-6Al-4V and b) EBM Ti-6Al-4V substrate with 7 $\mu \mathrm{m}$ thick AlN coating (ALD + CVD) during cyclic oxidation for 42, 227 and $489 \mathrm{~h}$. $\mathrm{TiO}_{2}$ rutile, $\star \mathrm{AlN}, \mathrm{O} \mathrm{Al}_{2} \mathrm{O}_{3}, \boldsymbol{\Delta} \alpha-\mathrm{Ti},+\mathrm{TiN}$ and $\times \mathrm{Ti}_{2} \mathrm{~N}$.

Fig. 10. Chemical cartography (EDS) of the cross section of AlN-coated Ti-6Al-4V after 490 h of cyclic oxidation under air. $1 . \mathrm{Al}_{2} \mathrm{O}_{3}, 2$. AlN, 3. N-diffusion zone, 4. Ti-6Al-4V. The nitrogen and titanium measurements are not reliable when both elements are in presence because of interferences between $\operatorname{Ti}(\mathrm{L})$ and $\mathrm{N}(\mathrm{K})$ peaks. Therefore, $\mathrm{N}$ contents in the Ti-6Al4V zone can be considered as background as checked on raw Ti-6Al-4V substrate.

Fig. 11. 3D Ti-6Al-4V lattice structure with AlN coating and SEM cross-section observations in BSE. The light grey contrast is due to the Ti-6Al-4V substrate. The AlN coating is observed in dark contrast 


\section{Figures}

a)

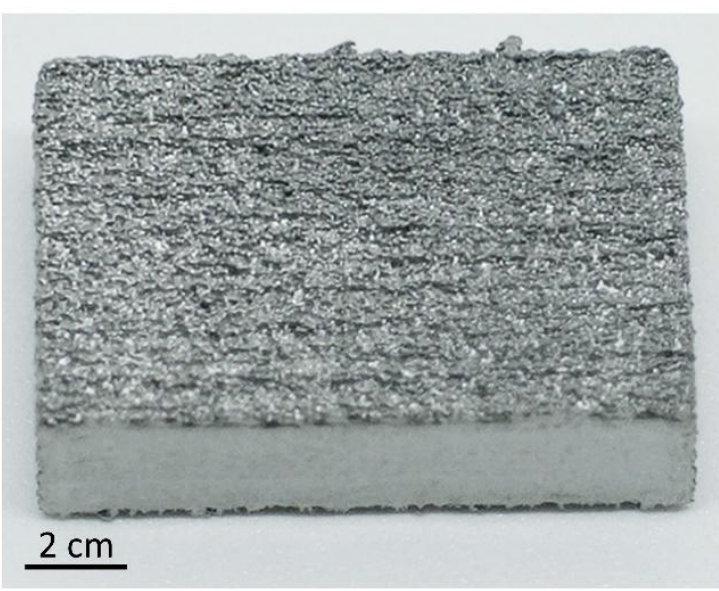

c)

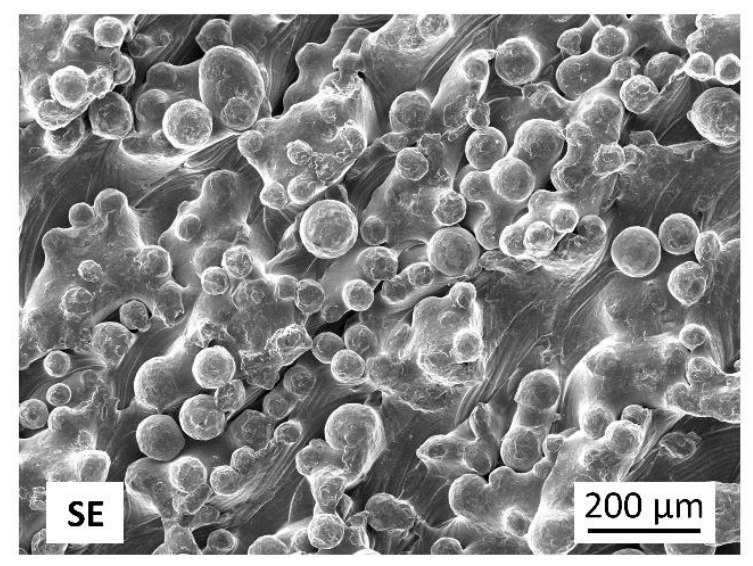

b)

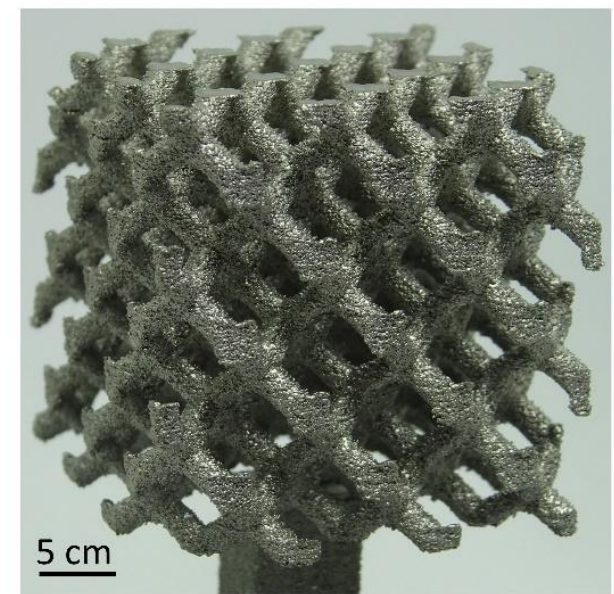

d)

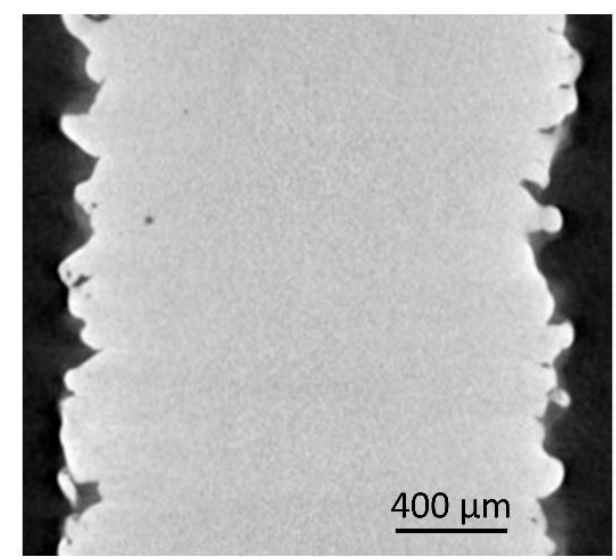

Fig. 1

a)

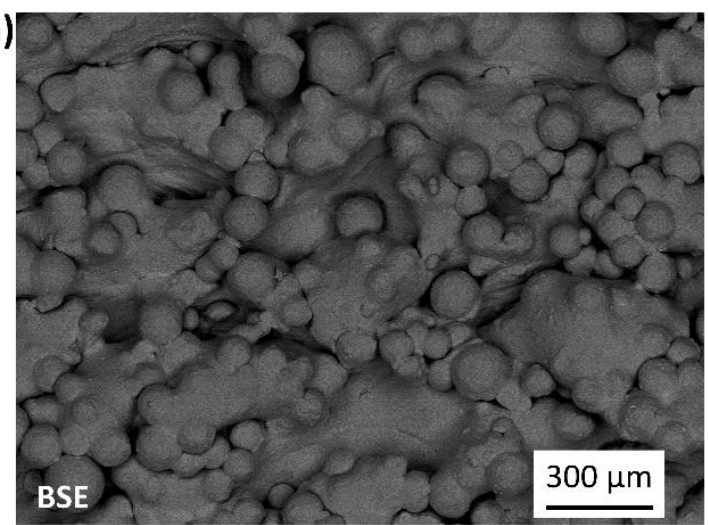

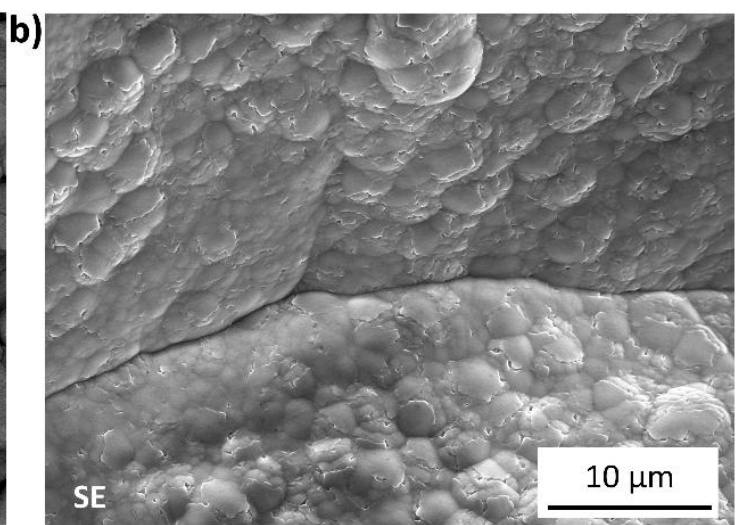

Fig. 2 

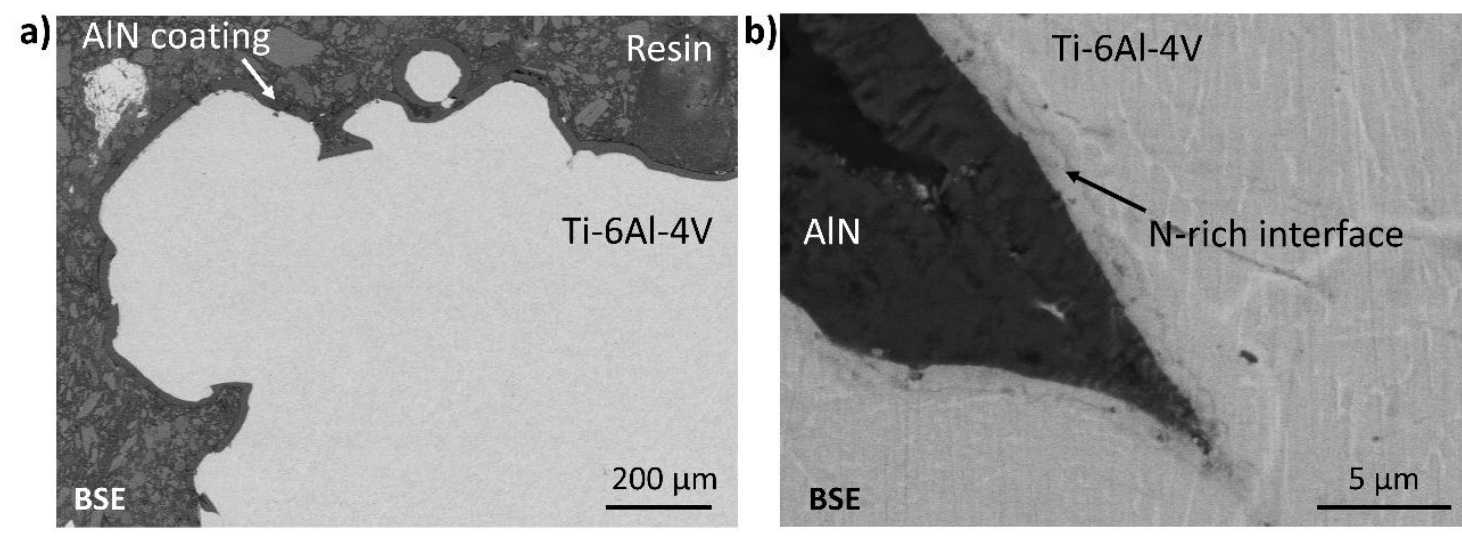

Fig. 3

a)

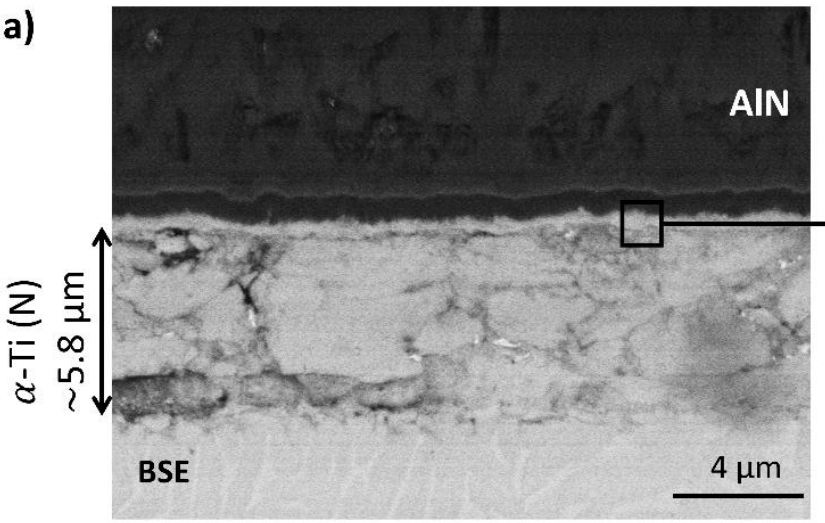

b)

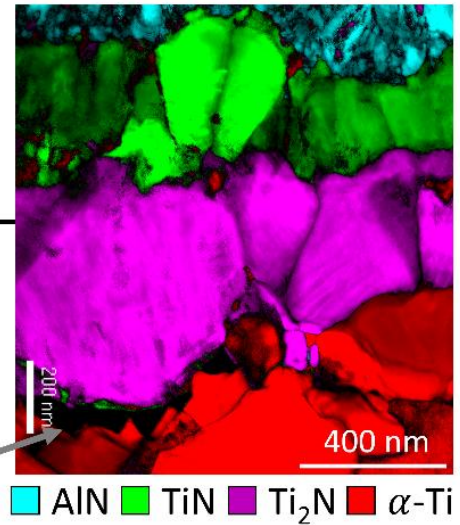

Fig. 4

a)

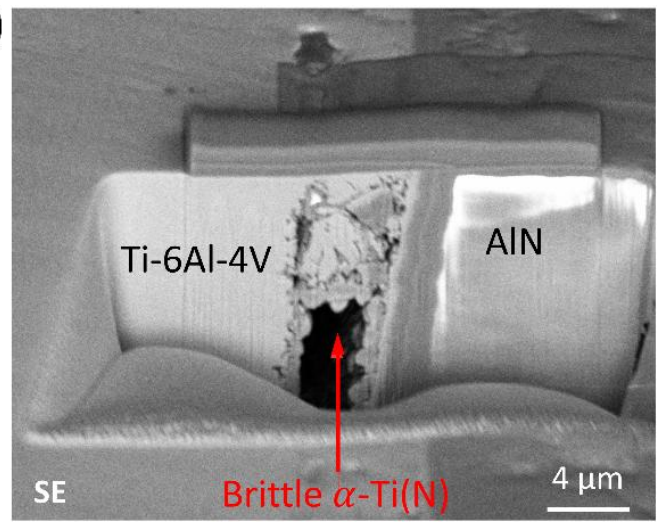

b)

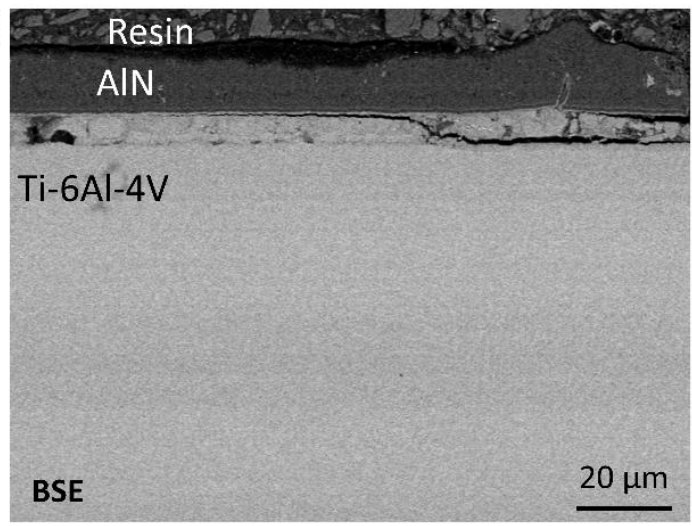

Fig. 5 
a)
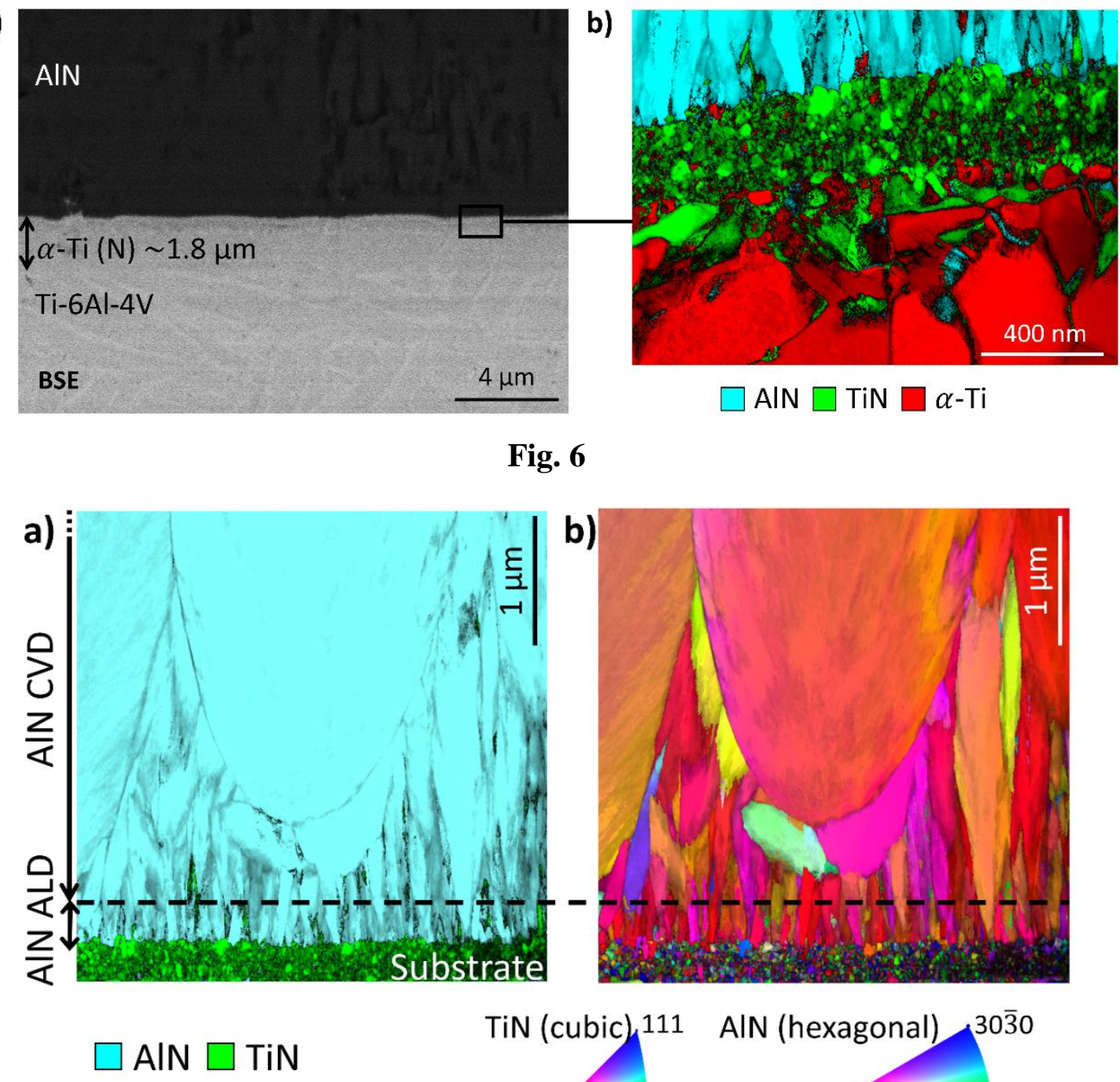

Fig. 6

b)

b)

$\square$ AIN $\square \operatorname{TiN} \square \alpha$-Ti

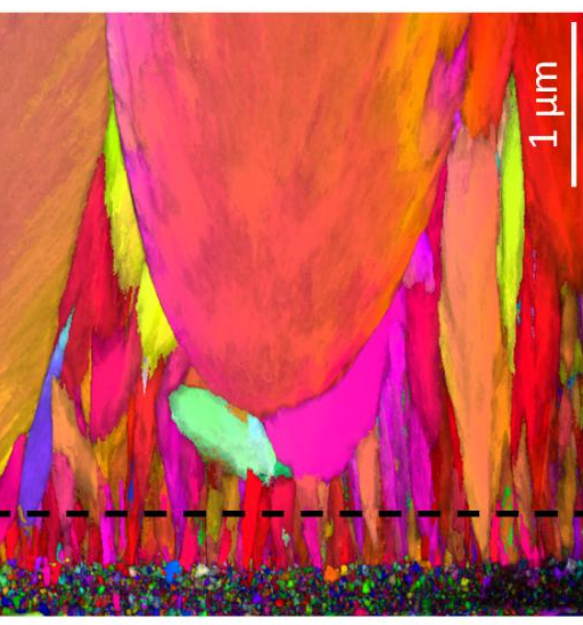

Substrate

AIN (hexagonal) $30 \overline{3} 0$

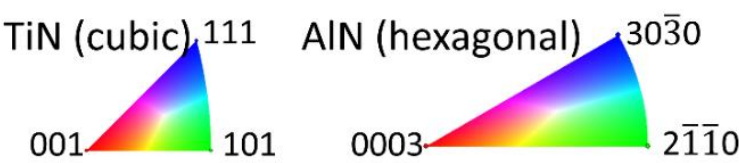

Fig. 7

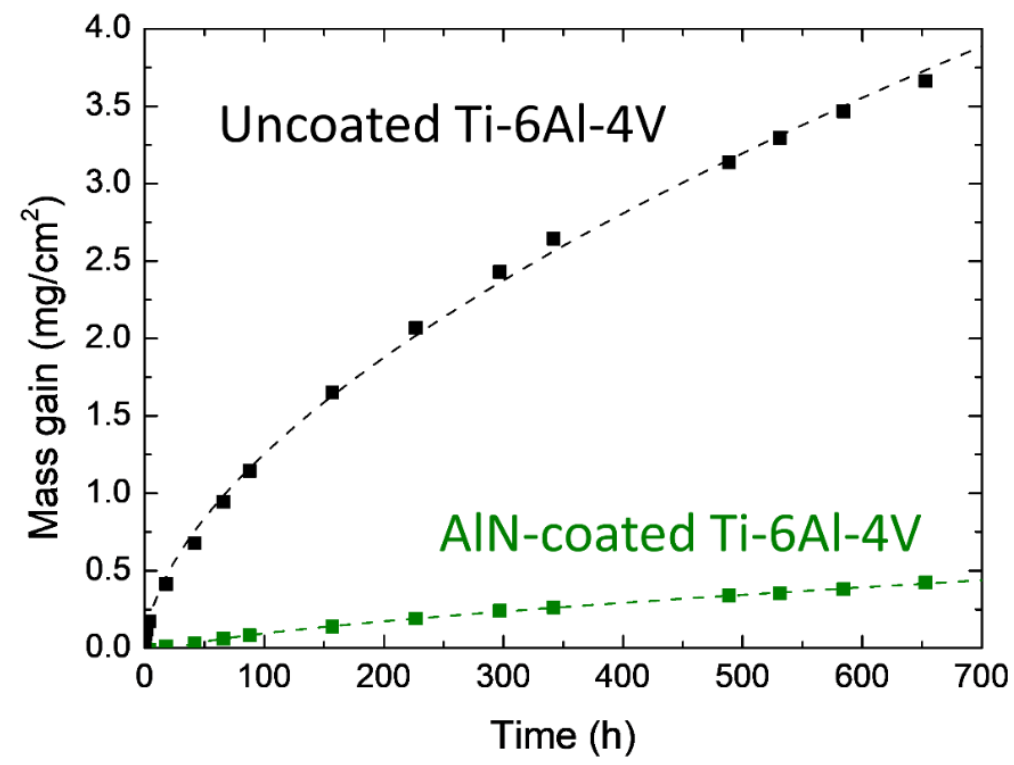


Fig. 8

a)

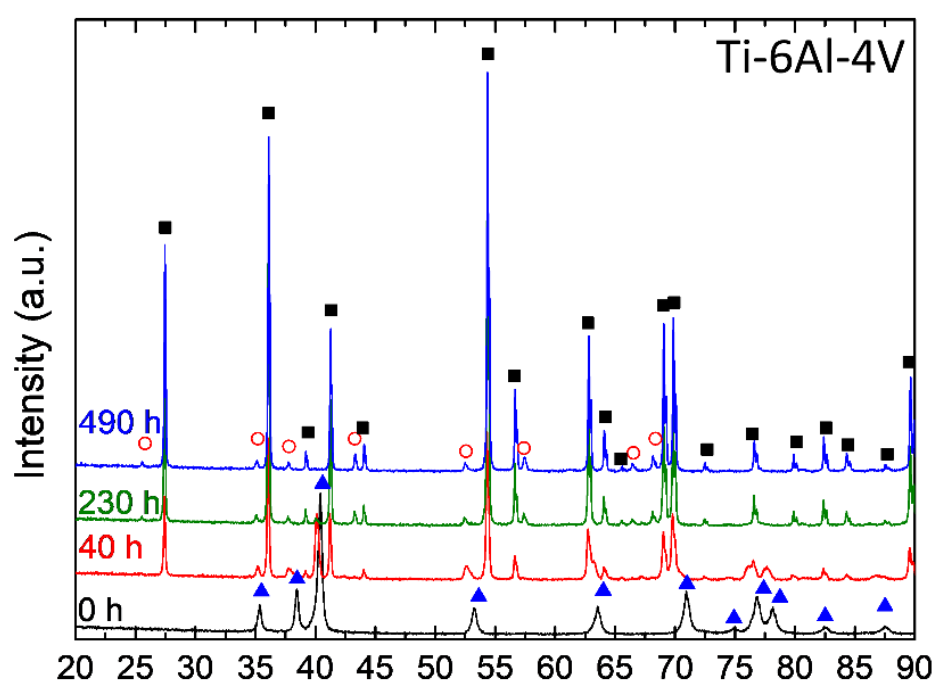

b)

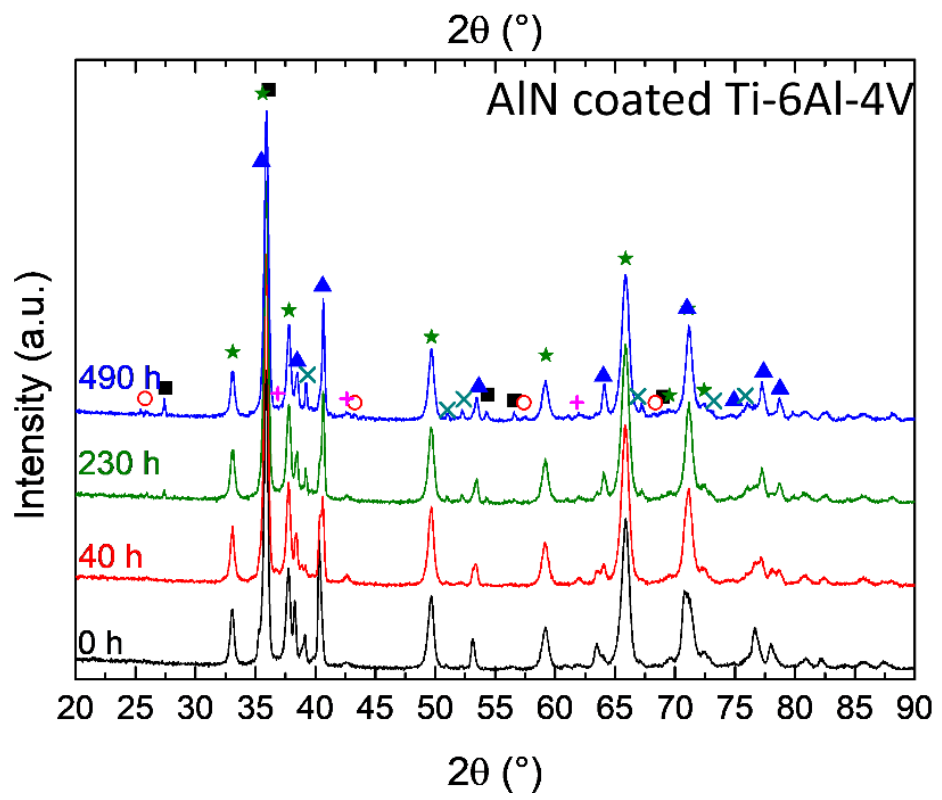

Fig. 9 




Fig. 10

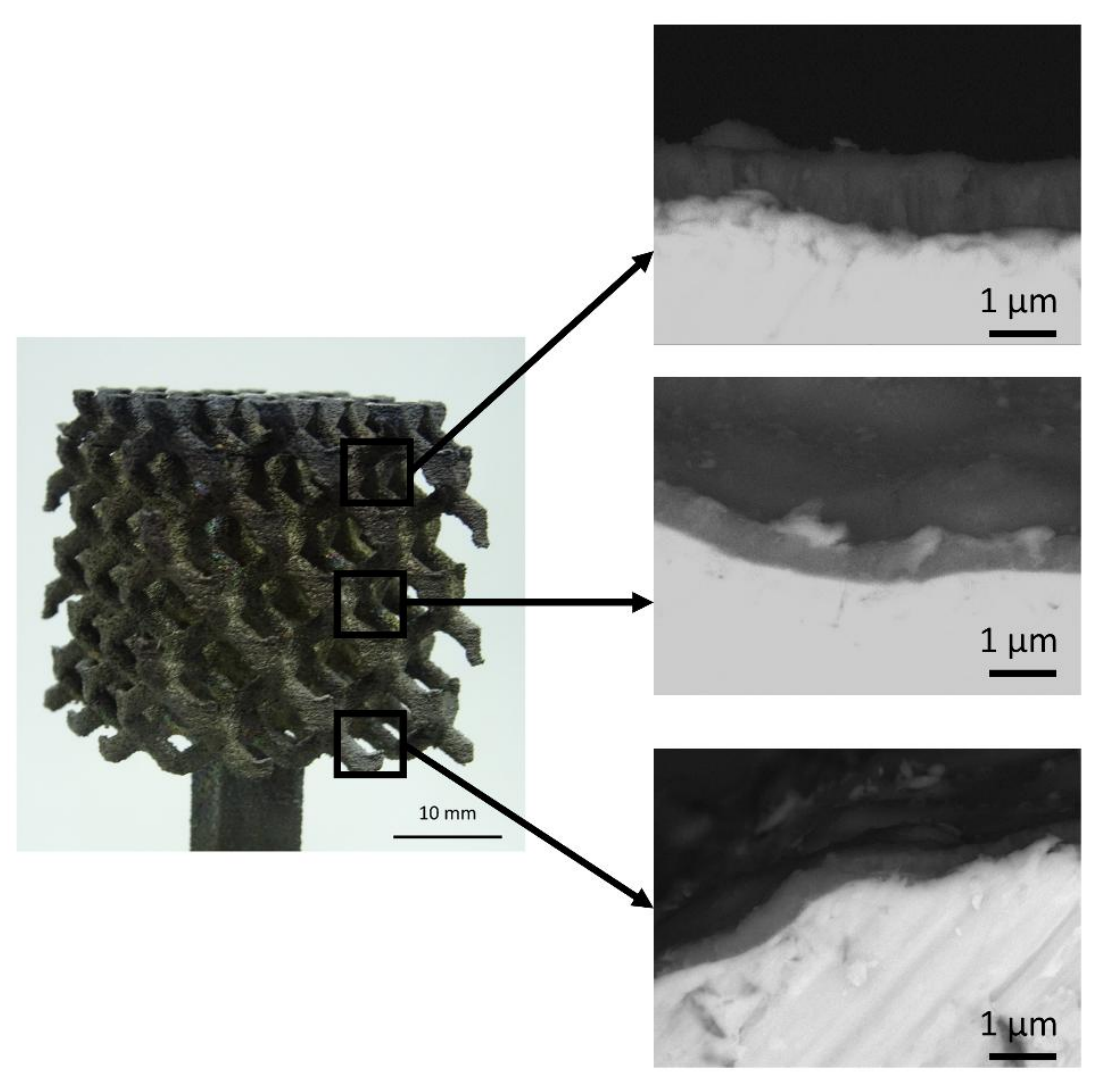

Fig. 11 